Research Article

\title{
A cross-sectional observational study to assess awareness of pharmacovigilance among interns of a teaching medical institute in western Maharashtra
}

\author{
Ajitkumar M. Zende ${ }^{1 *}$, Umesh Y. Bhoi ${ }^{2}$, Nitin N. Puram ${ }^{1}$
}

\author{
${ }^{1}$ Department of Pharmacology, \\ R.C.S.M. GMC, Kolhapur, \\ Maharashtra, India, \\ ${ }^{2}$ Department of Skin \& V.D, \\ R.C.S.M. GMC, Kolhapur, \\ Maharashtra, India
}

Received: 23 December 2015 Accepted: 03 February 2016

\section{*Correspondence to: \\ Dr. Ajitkumar M. Zende, Email: drajitzende10@ gmail.com}

Copyright: (C) the author(s), publisher and licensee Medip Academy. This is an openaccess article distributed under the terms of the Creative Commons Attribution NonCommercial License, which permits unrestricted noncommercial use, distribution, and reproduction in any medium, provided the original work is properly cited.

\begin{abstract}
Background: Adverse Drug reaction (ADR) is one of the most serious health problems and remains an important cause behind treatment non-adherence and treatment failure. Voluntary reporting of ADRs is fundamental basis of Pharmacovigilance and Drug safety. However, underreporting of ADRs remains hindrance to Pharmacovigilance practice. Hence the present study was conducted to assess awareness regarding Pharmacovigilance in Interns.

Methods: A cross-sectional questionnaire-based survey was conducted in Interns at tertiary care hospital of Western Maharashtra.

Results: Questionnaire was analyzed at the Response Rate of $87.5 \%$. Interns were having good knowledge $(52.42 \%)$ and practices $(50 \%)$ about Pharmacovigilance. Majority of interns $(85.75 \%)$ possess correct attitude towards Pharmacovigilance. All the interns $(100 \%)$ are of opinion that it is important to report the ADRs. Majority of the interns $(97.60 \%)$ suggest that it should be mandatory to have an ADR reporting center in each institute. Most of them $(59.52 \%)$ feel that there should be some incentive to report an ADR and $90.47 \%$ of Interns want to get trained in ADR reporting.

Conclusions: Awareness and Practice of Pharmacovigilance can be improved by proper training of interns about ADR reporting. We strongly recommend the introduction of ADR reporting in the internship orientation program.
\end{abstract}

Keywords: ADRs, Awareness, Interns, Pharmacovigilance

\section{INTRODUCTION}

In day to day clinical practice we observe the usual tendency of the clinicians to prescribe newer drugs, but they do not spend any extra time in reporting ill effects or observed adverse drug reactions (ADRs). This affects the safe use of the drugs and we all know that ADRs is one of the common causes of human morbidity and mortality. It is estimated that only 6-10\% of all ADRs are reported and under reporting of ADRs by health care professionals is a major problem. ${ }^{1}$

The information collected during the premarketing phase of a drug is inevitably incomplete with regards to possible ADRs. This occurs because tests in animals are insufficiently predictive of human safety and in human studies the patients are selective, limited in number and the duration of the study is also limited. ${ }^{2}$ So after marketing of a drug, the surveillance regarding its safety and efficacy is important when the drug is used in large number of population. This will give the practical accounts about the safety of the drug and will also promote the safer use of drugs.

With experience of Thalidomide disaster in 1961, WHO established its programme for internal drug monitoringThe Pharmacovigilance (P.V.). Pharmacovigilance is defined as the science and activities relating to the 
detection, assessment, understanding and prevention of adverse drug reaction.

Appropriate time of acquiring pharmacovigilance knowledge and attitude is probably during initial period of establishing clinical practice. Internship is the period in life of every medical graduate where they acquire most of attitude about their professional environment. So in this context we decided to assess awareness of interns in our tertiary care hospital and teaching institute about pharmacovigilance.

\section{METHODS}

Survey was conducted amongst the interns. It was a cross sectional knowledge, attitude and practice (KAP) questionnaire based study carried out after approval from the Institutional Ethics Committee (IEC). Informed consent was obtained from each participant. A newly developed and pre-validated KAP questionnaire was used. It consisted of a total number of 20 questions. Among these 6 questions were related to the Knowledge, 7 questions were related to Attitude and remaining 7 were related to the Practice aspects. The initial draft was circulated to the members of the research team, tutors and modifications were carried out as per the suggestions. Every intern was given 20 minutes to fill the questionnaire. Any clarification needed in understanding the questionnaire was provided. In order to preclude any potential bias, the disclosure of name of the responder was made optional. Initially KAP questionnaire was briefed to all participants and they were informed about the purpose of the study. KAP questionnaire was analyzed question-wise and their percentage value calculated. In case of unanswered questions, the participant was excluded from the study. Data was analyzed using descriptive statistics with Microsoft excel for windows 10 .

\section{RESULTS}

The study was conducted in a teaching institute and tertiary care hospital situated in west Maharashtra. A total of 96 interns participated in the study of which actually 84 were enrolled as respondents. The major reason for not enrolling 12 interns in the study was unanswered questions in survey questionnaire.

Table 1: KAP Score of respondent.

\begin{tabular}{|lllll|}
\hline $\begin{array}{l}\text { Survey } \\
\text { Parameters }\end{array}$ & $\begin{array}{l}\text { Mean } \\
\text { Score } \\
(\mathbf{n = 8 4})\end{array}$ & $\begin{array}{l}\text { Score Range (0-7) } \\
\text { Poor } \\
\mathbf{( 0 - 2 )}\end{array}$ & $\begin{array}{l}\text { Good } \\
\mathbf{( 3 - 4 )}\end{array}$ & $\begin{array}{l}\text { Excellent } \\
\mathbf{( 5 - 7 )}\end{array}$ \\
\hline Knowledge & 4.14 & $2.35 \%$ & $52.42 \%$ & $45.23 \%$ \\
\hline Attitude & 6.04 & $2.35 \%$ & $11.90 \%$ & $85.75 \%$ \\
\hline Practice & 4.28 & $7.15 \%$ & $50 \%$ & $42.85 \%$ \\
\hline
\end{tabular}

The knowledge, attitude and practices based questions were grouped and scores were determined as depicted in
Table 1. Interns have displayed good knowledge $(52.42 \%)$ and sound practices $(50 \%)$ about Pharmacovigilance. Majority of interns $(85.75 \%)$ possess correct attitude towards Pharmacovigilance. The mean scores also suggest that intern's awareness about Pharmacovigilance in relation with knowledge, attitude and practices is good.

Table 2 shows the awareness of interns about adverse drug reactions. All $(100 \%)$ the interns are of opinion that it is important to report the ADRs, however, most $(76.20 \%)$ of them are unaware of the existence of Pharmacovigilance Committee in their institute where ADRs can be reported. Majority $(97.60 \%)$ of the interns feel that ADR reporting is a professional obligation for them. Though all of them are of the opinion that it is important to report the ADRs of all types, only $33.33 \%$ have reported them when they have seen a patient with ADR. 78.57\% interns say that they have seen the patients with ADRs but of all interns, $66.67 \%$ don't have reported any ADR yet.

Table 2: Awareness of Respondent about ADRs.

\begin{tabular}{|c|c|c|c|c|}
\hline \multirow{2}{*}{\multicolumn{2}{|c|}{ Questions }} & \multicolumn{3}{|c|}{ Response $(n=84)$} \\
\hline & & \multirow{2}{*}{$\begin{array}{l}\text { Yes } \\
100 \%\end{array}$} & \multirow{2}{*}{$\begin{array}{l}\text { No } \\
0 \%\end{array}$} & \multirow{2}{*}{$\begin{array}{l}\text { I don't } \\
\text { know } \\
0 \%\end{array}$} \\
\hline 1 & $\begin{array}{l}\text { Is it important to } \\
\text { report an Adverse } \\
\text { Drug Reaction? }\end{array}$ & & & \\
\hline 2 & $\begin{array}{l}\text { Is there any } \\
\text { Pharmacovigilance } \\
\text { committee in your } \\
\text { institute/hospital? }\end{array}$ & $19.04 \%$ & $4.76 \%$ & $76.20 \%$ \\
\hline 3 & $\begin{array}{l}\text { Are you afraid of } \\
\text { reporting an } \\
\text { Adverse Drug } \\
\text { Reaction? }\end{array}$ & $2.4 \%$ & $97.60 \%$ & - \\
\hline & $\begin{array}{l}\text { Have you ever } \\
\text { seen a patient with } \\
\text { Adverse Drug } \\
\text { Reaction? }\end{array}$ & $78.57 \%$ & $21.43 \%$ & - \\
\hline & $\begin{array}{l}\text { Have you ever } \\
\text { reported a patient } \\
\text { with Adverse } \\
\text { Drug Reaction? }\end{array}$ & $33.33 \%$ & $66.67 \%$ & - \\
\hline
\end{tabular}

As shown in Figure $1 \& 2$, majority of the interns (91\%) are aware that all types of ADRs, irrespective of their nature, should be reported and most of them $(83.34 \%)$ are of opinion that ADR reporting should be made mandatory to all health care professionals.

As seen in Table 3, most of the interns (97.60\%) suggest that it should be mandatory to have an ADR reporting center in each institute. Majority of them (59.52\%) feel that there should be some incentives to report an ADR. Since they are knowing the importance of ADR reporting, all are of the opinon that it is not an 
unnnecessary burden on them to report ADR and for that majority of them $(90.47 \%)$ want to get trained in ADR reporting.

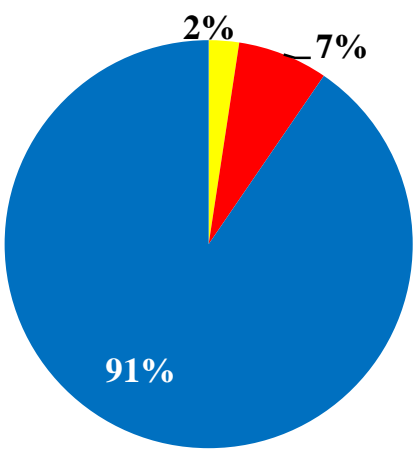

Figure 1: Type of ADRs to be reported according to respondents.



Figure 2: Reporting of ADRs according to respondent.

Table 3: Attitude of respondent about ADRs.

\begin{tabular}{|llll|}
\hline Questions & \multicolumn{3}{c|}{ Response (n=84) } \\
& Yes & No & $\begin{array}{l}\text { I don't } \\
\text { know }\end{array}$ \\
\hline $\begin{array}{l}\text { Should it be } \\
\text { mandatory to have } \\
\text { an Adverse Drug } \\
\text { Reaction reporting } \\
\text { centre in each } \\
\text { hospital/Institute? }\end{array}$ & $97.60 \%$ & $2.40 \%$ & $0 \%$ \\
\hline $\begin{array}{l}\text { Should there be any } \\
\text { incentives to report } \\
\text { an adverse drug } \\
\text { reaction? }\end{array}$ & $59.52 \%$ & $30.96 \%$ & $9.52 \%$ \\
\hline $\begin{array}{l}\text { Do you think that } \\
\text { Adverse Drug } \\
\text { Reaction reporting is } \\
\text { an unnecessary } \\
\text { burden on healthcare } \\
\text { providers? }\end{array}$ & $2.4 \%$ & $97.60 \%$ & - \\
\hline $\begin{array}{l}\text { Do you need the } \\
\text { training about } \\
\text { adverse drug } \\
\text { reaction reporting }\end{array}$ & & & \\
\hline
\end{tabular}

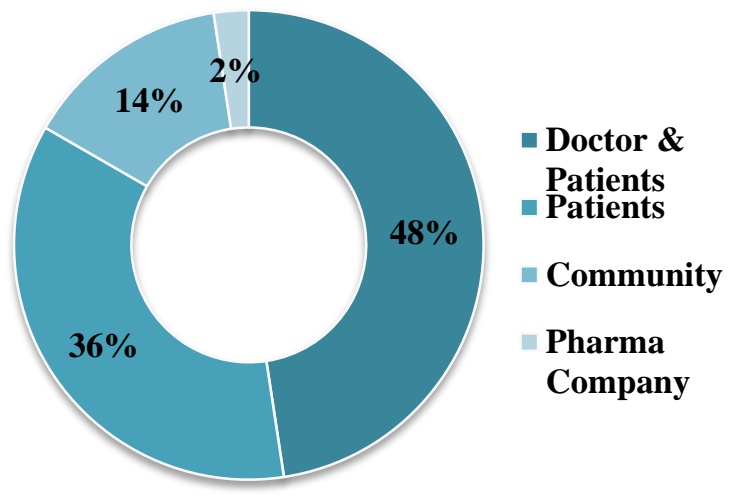

Figure 3: Benefits of ADRs reporting according to respondent.

As shown in Figure 3, $48 \%$ interns say that both doctors and patients will get benefitted due to ADR reporting while very few $(14 \%)$ say that the community will be benefitted.

\section{DISCUSSION}

Safe use of drugs and consequent safety of patient's health should be the prior aim of any therapy. ADR is one of the most serious health problems and remains an important cause behind treatment non-adherence and treatment failure. So ADR reporting has gained very much importance for safer use of drugs.

Since the clinical trials are conducted in controlled environment, in small number of volunteers and selected group of patient, they are insufficiently predictive of safety of drugs in human. But after marketing when the drug is used by large no of patients of different ages, sex, with co-morbid conditions and co-administered drugs, the scenario becomes quite complicated. In such situations the drug may produce unusual ADRs which are never seen during drug trials. So to gather additional safety information about drugs, continuous reporting of the encountered ADRs is essential. The interns are valuable source for collecting, analysing and reporting ADRs. They play major role in interacting with patients and their peers in the clinical departments and so in this context we thought to assess knowledge, attitude and practices of interns (future clinicians) about Pharmacovigilance. To facilitate the activity of Pharmacovigilance, a culture of learning about it should start early in professional training.

In present study we observed that respondents were having adequate knowledge and favourable attitude about Pharmacovigilance, however, they were lacking in the practice of the same i.e. how to report an ADR. Similar conclusions were drawn by a study conducted about awareness of Pharmacovigilance among dental interns by Madhavrao C, et al. ${ }^{3}$ Majority respondents $(91 \%)$ in our study stated that all types of ADRs irrespective of type of ADR should reported. Similar observations were made by 
Manjunath SM, et al where extent of awareness among fifth term medical students was assessed and it was noted that $66.67 \%$ students agreed to report all types of ADRs. ${ }^{4}$

In our study majority of interns $(78.57 \%)$ stated that all doctors, nurses and pharmacists can report ADRs and same finding was reported in a study by Gangadhar M, et al. ${ }^{5}$ Further majority of interns $(76.20 \%)$ were not aware about presence of Pharmacovigilance committee in the institute and similar findings were observed by Sharma $S$, et al in their study which comprised of 146 respondents. ${ }^{6}$ Same study also reported that $62.5 \%$ senior and $45.5 \%$ junior doctors recommended for remuneration for ADRs reporting, also $87.5 \%$ \& $68.2 \%$ senior and junior doctors respectively suggested about training of all health care professionals about ADR reporting. Somewhat similar findings were seen in our study about incentives (78.57\%) and training of ADR reporting (90.47\%).

A study conducted by Rehan $\mathrm{H} \mathrm{S}$, et al showed that reporting of ADRs is essential by prescribers (82\%) and undergraduate students $(64.5 \%){ }^{7}$ Similar observations were observed in our study where $83.34 \%$ respondents were positive about necessity of ADR reporting.

In our study, majority of interns $(97.60 \%)$ said that it should be mandatory to have ADR reporting center in each hospital or medical teaching institute but observation regarding same in a study by Torwane $\mathrm{N}$, et al was different and stated that only $40.56 \%$ healthcare professionals felt that ADR monitoring center should be established in every hospital. ${ }^{8}$ These findings are indicative of relatively positive attitude of younger generation towards Pharmacovigilance.

Our study is limited to assess the awareness of Pharmacovigilance in interns only but to achieve the aims of Pharmacovigilance and to make national Pharmacovigilance program a success, further similar studies are needed to be carried out in other teaching hospitals, private practitioners, allied field workers and in medical students.

\section{CONCLUSION}

With this study we finally conclude that the interns are having adequate knowledge and favorable attitude towards pharmacovigilance but they are lacking in the practice of pharmacovigilance. This can be improved by imparting proper training to the interns regarding ADR reporting. We strongly recommend that training of ADR reporting should be introduced in the internship orientation program.

\section{Funding: No funding sources \\ Conflict of interest: None declared \\ Ethical approval: The study was approved by the Institutional Ethics Committee}

\section{REFERENCES}

1. Bansode A, Zad V, Sawant S, Dudhal K. Awareness about Pharmacovigilance among Resident Doctors in a Tertiary Care Hospital. Journal of Evolution of Medical and Dental Sciences. 2015;4(2):207-10.

2. Pugsley MK, Authier S, Curtis MJ. Principles of Safety Pharmacology. $\mathrm{Br} \mathrm{J}$ of Pharmacol. 2008;154(7):1382-99.

3. Madhavrao C, Mythili Bai K. Awareness of pharmacovigilance among dental interns in a southern tertiary care hospital. European Journal of Biomedical and Pharmaceutical sciences. 2015;2(6):193-6.

4. Manjunath SM, Nagesh Raju G, Someswara GM. A cross-sectional study on the extent of Pharmacovigilance awareness among fifth term medical students. IAIM. 2015;2(9):94-101.

5. Gangadhar M, Guruppanavar D. Assessment of knowledge, attitude and perception of Pharmacovigilance among nurses in a rural tertiary care center. Int $\mathbf{J}$ Basic Clin Pharmacol. 2015;4:1009-12.

6. Sharma S, Phadnis P, Gajbhiye S. Pharmacovigilance: Its awareness and impact Study in a tertiary care teaching medical college in central India. IJPRBS. 2013;2(3):234-47.

7. Rehan HS, Sah RK, Chopra D. Comparison of Knowledge, Attitude and Practices of Resident doctors and nurses on adverse drug reaction monitoring and reporting in tertiary care hospital. Indian J Pharmacol. 2012;44(6):699-03.

8. Torwane N, Hongal S, Gouraha A, Jain S, Chavan K, Dayma A. Assessment of knowledge, attitude and practice related to Pharmacovigilance among the healthcare professionals in a teaching hospital in central India: A questionnaire study. WJPPS. 2015;4(4):785-99.

Cite this article as: Zende AM, Bhoi UY, Puram NN. A cross-sectional observational study to assess awareness of pharmacovigilance among interns of a teaching medical institute in western Maharashtra. Int J Basic Clin Pharmacol 2016;5:374-7. 